\title{
Epidemiology of Depression, Anxiety and Stress Symptoms in Veterans' Wives
}

\section{ART ICLE INF O}

\section{Article Type}

Descriptive Study

\section{Authors}

Seyyed Talebi S.M.* $M S c$

Rafieepour A. ${ }^{1} \mathrm{PhD}$

\section{A B S T R A C T}

Aims To the parents and adolescents, the adolescence period is full of stressful situations. The children of the veterans undergoing mental pressures due their veteran fathers' emotional avoidance continuously during all their mental.

Instrument \& Methods In the controlled pretest-posttest experimental study, 30 female highschool students of the veterans' families in Isfahan were studied in the academic year 2015-16. The subjects, selected via cluster random.

Findings At the posttest stage, the mean scores of the groups were significantly different including the relationship components (dialogue), paternal engagement, and anger $(p<0.05)$. Nevertheless, the groups were not significantly different in the positive emotion component ( $\mathrm{p}>0.05)$.

Conclusion The positive-thinking skills trainings can improve the paternal engagement, dialogue, and anger in the female students of the veterans' families. Such trainings can also enhance their mental health quality.

Keywords Spouse; Demography; Epidemiology; Depression; Anxiety; Stress

\section{CIT A T I O N LINKS}

[1] Children's exposure to community and war violence and mental health in four African ... [2] Determinants of geriatric patients' quality of life after stroke ... [3] Quality of life and burden in caregivers of patients with ... [4] Recent research on Gulf War illness and other health problems in veterans of the 1991 Gulf War: Effects of toxicant exposures ... [5] Post-traumatic stress disorder among wives of Kuwaiti veterans of the first ... [6] Women partners of Vietnam ... [7] Posttraumatic stress disorder and depression in battle-injured ... [8] PTSD symptom clusters in relationship to alcohol misuse among Iraq and Afghanistan war veterans seeking post-deployment VA health care ... [9] The effectiveness of spiritual and existential group therapy on the rates of depression, death anxiety and afterlife belief among students: a study based on the reports of people ... [10] Being a wife of a veteran with posttraumatic stress ... [11] Health and marital satisfaction among Iranian women married to veterans and ... [12] Damages in families of male Vietnam veterans with posttraumatic ... [13] The Comparison of the quality of life of the war veterans families with/without Post traumatic stress ... [14] Quality of life in chemical warfare victims with ophthalmic damage's ... [15] Assessment of relationship quality of life and coping skills in spouses of chemical devotees with pulmonary complications due to ... [16] Evaluation of mental health state in ... [17] Comparativeinvestigation ofmentalhealthstatus of spouses ofwarhandicapsinaccordance with husband's ... [18] Mental health in a group of war veterans and their spouses in ... [19] The effect of training conflict resolution on quality of life's on spouses of war veterans post traumatic stress disorder [20] Mental health in a group of war veterans and their spouses... [21] Quality of life in spouses of war related bilateral lower limb ... [22] Determining sample size for research ... [23] The intracluster correlation coefficient in cluster ... [24] An inventory for measuring clinical anxiety ... [25] An inventory for measuring depression ... [26] SCL 90 R administration, scoring and procedures ... [27] Mediating role of self-esteem on the relationship ... [28] Manual for the depression anxiety stress ... [29] Psychometric properties of the 42-item and 21-item versions of the ... [30] Personality and conflict communication patterns ... [31] Psychometric properties of the Depression [32] Validation of depression anxiety and ... [33] Anxiety, depression and quality of life [34] From psychological stress to emotions ... [35] Scales of measuring anxiety ...

\section{Article History}

Received: Fabruary 6, 2017

Accepted: March 14, 2017

ePublished: July 27, 2017 uchestan, Zahedan, Iran

Copyright(C) 2017, ASP Ins. This open-access article is published under the terms of the Creative Commons Attribution-NonCommercial 4.0 International License which permits Share (copy and redistribute the material in any medium or format) and Adapt (remix, transform, and build upon the material) under the Attribution-NonCommercial terms. 
اما اثرات جنگ تا اعماق خانوادهها و جامعه نيز نفوذ ميكندا،

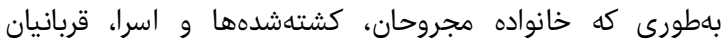

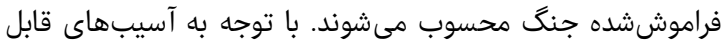

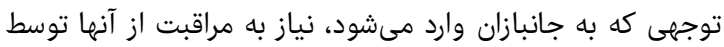

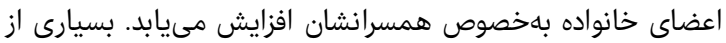

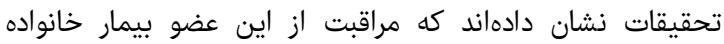

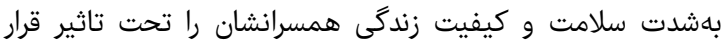

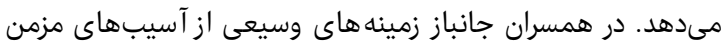

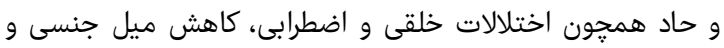

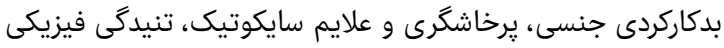

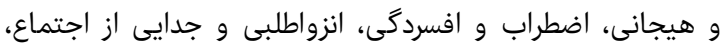

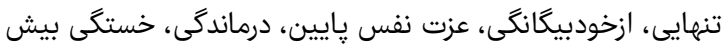

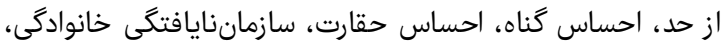

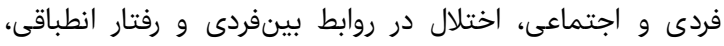
علايم شبهجسمى و جسمانىسازى، تبديلى و غيره مشاهده شده

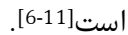

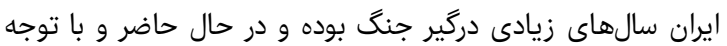

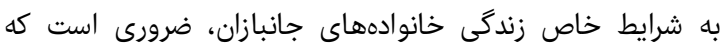

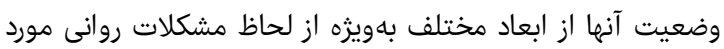

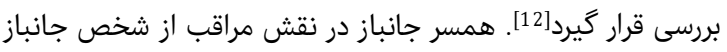

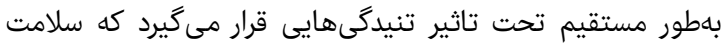

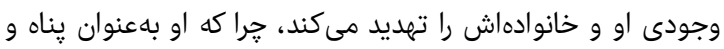

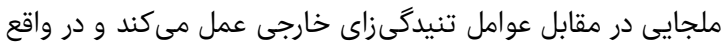

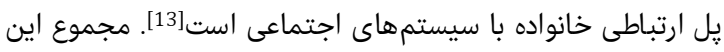

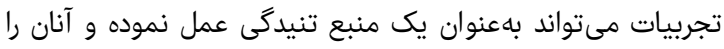

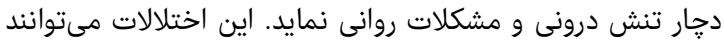

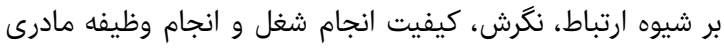

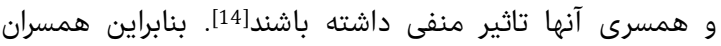

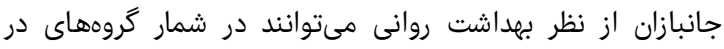
معرض خطر جامعه بهحساب آيند.

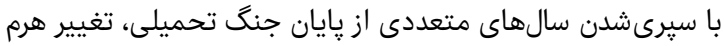

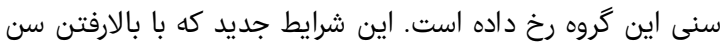

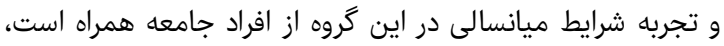

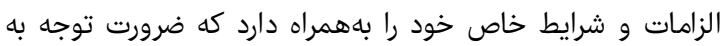

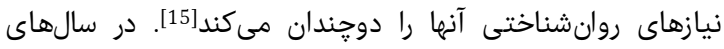

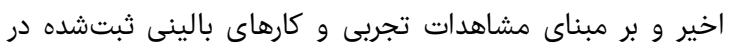

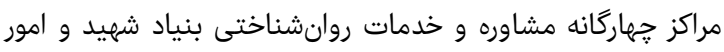

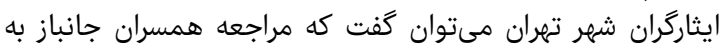

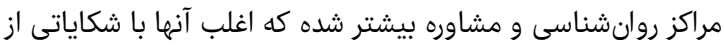

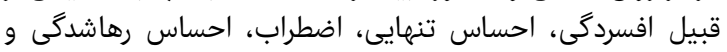

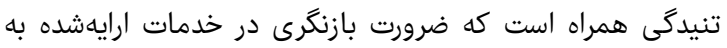

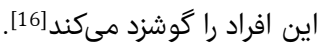

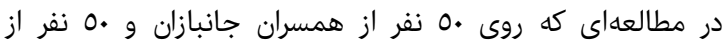

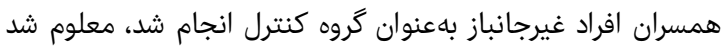

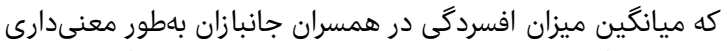

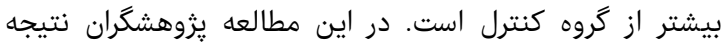

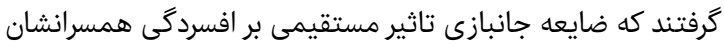

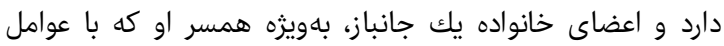

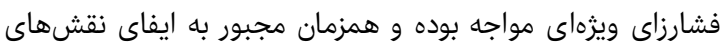

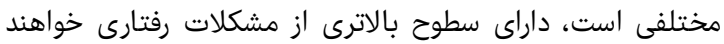

همهگيرشناسى نشانكان افسردگى، اضطراب و و تنيدگى در همسران جانبازان

MSc سيدمريم سيد طالبى

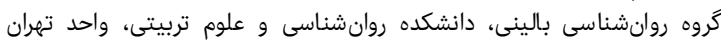

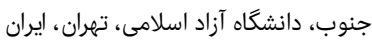

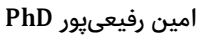
كروه روانشناسى، دانشور دانشده علوم تربيتى و روانشناسى، دانشكاه سيستان و

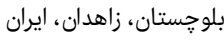

جكيده

اهداف: از عوارض مهم هر جنكى، بروز مشكلات جسمى و روانى براى

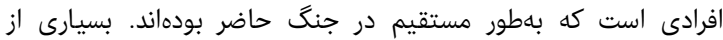

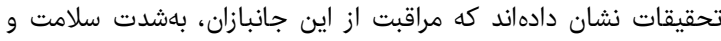

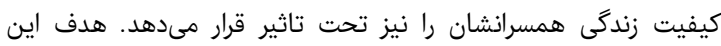

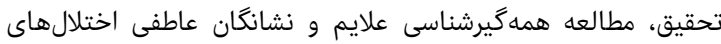

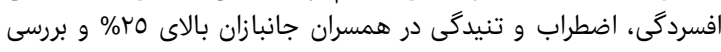

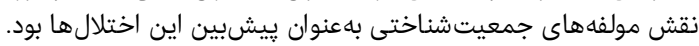

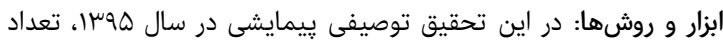

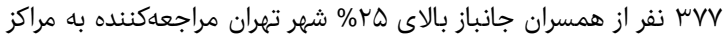

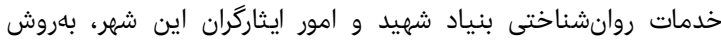

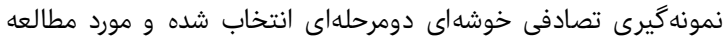

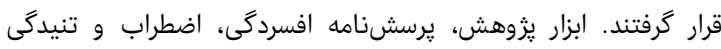

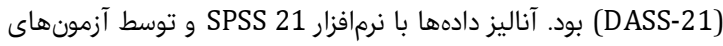

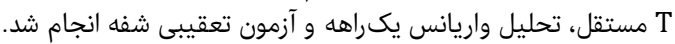

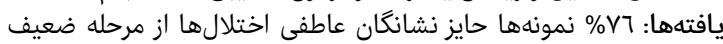

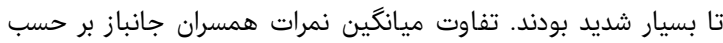

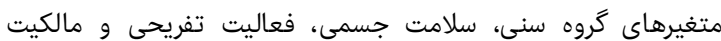

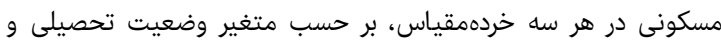

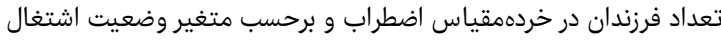

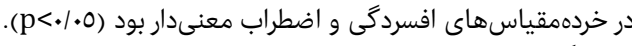

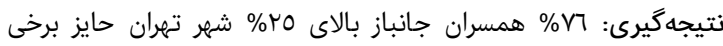

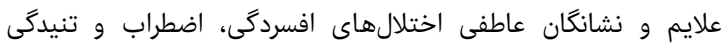

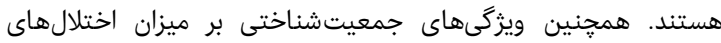

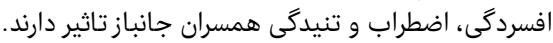

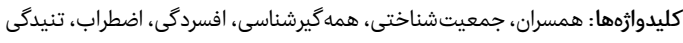

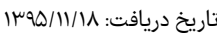

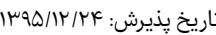

"نويسنده مسئول: تاريخ: smstalebi64@gmail.com

مقدمه - مقد

خانواده نهادى است كه به اعضاى خود احساس امنيت و آرامش بادي

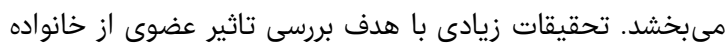

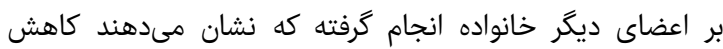

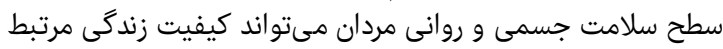

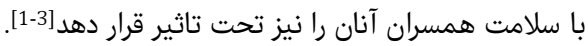

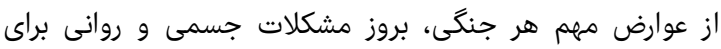

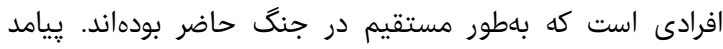

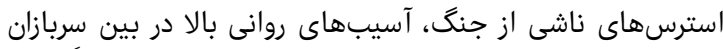

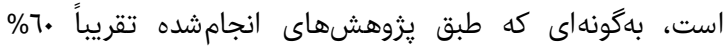

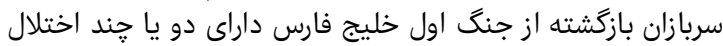

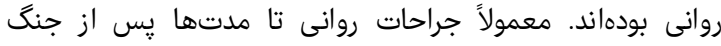

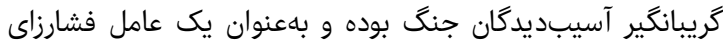

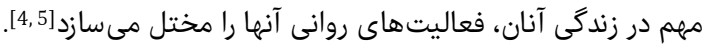




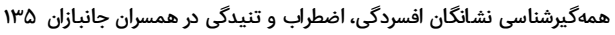

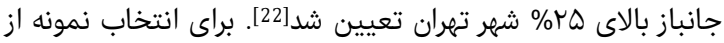

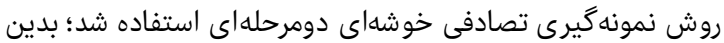

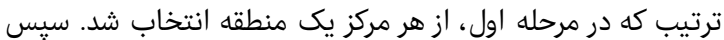

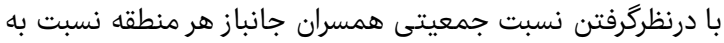

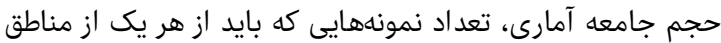

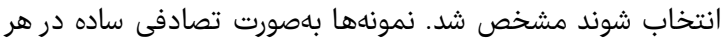

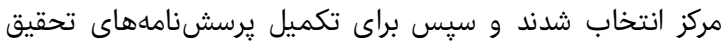

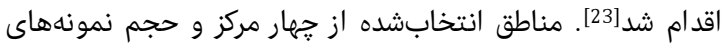
هر طبقه بهشرح ذيل بود:

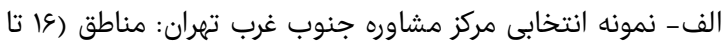

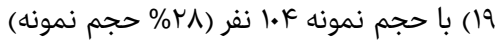

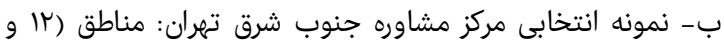

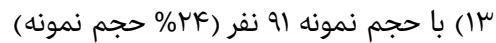

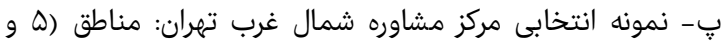

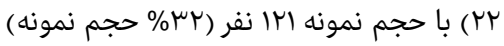

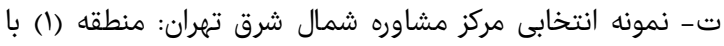

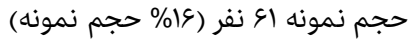

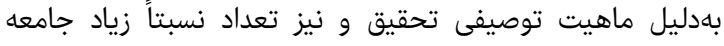

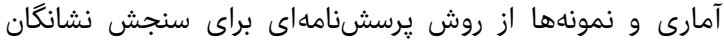

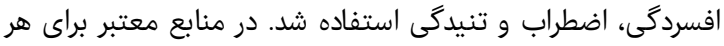

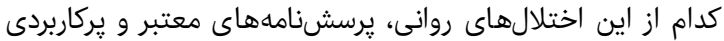

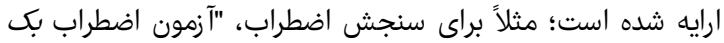

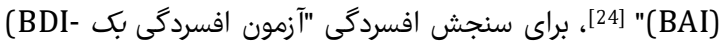
[25 " "II)

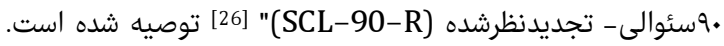

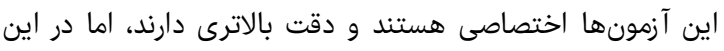

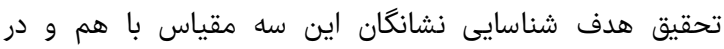

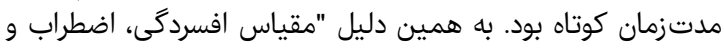

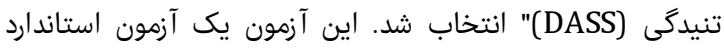

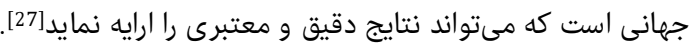

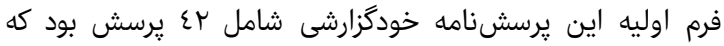

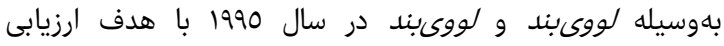

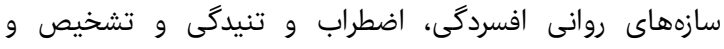

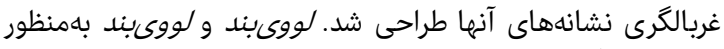

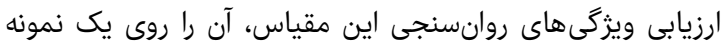

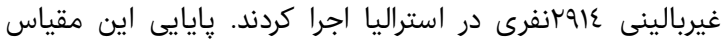

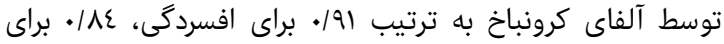

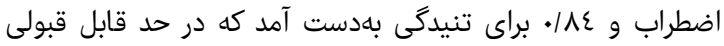

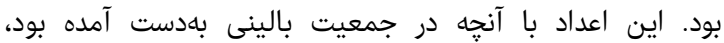

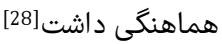

در سالهاى اخير بهعلت ضعفهاى دهاى موجود در برخى آيتمهاى

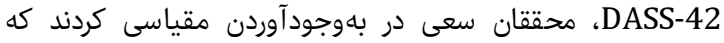

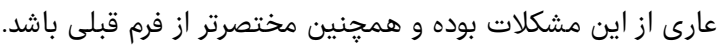

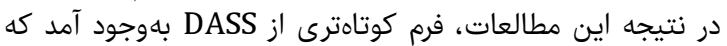

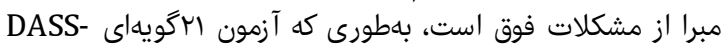

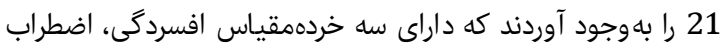

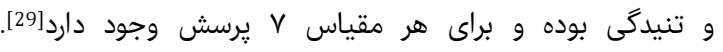

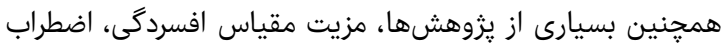

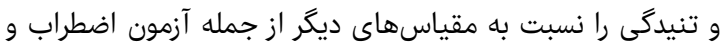

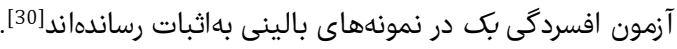

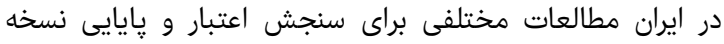

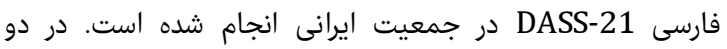

محققان نشان دادند كه بrN/9\% همسران جانبازان براساس آزمون

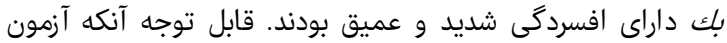

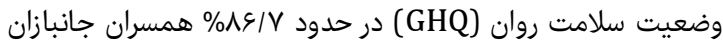

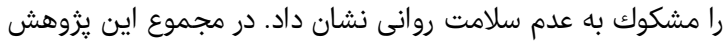

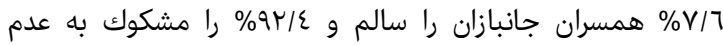

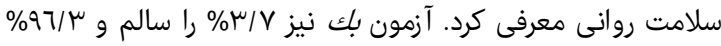
آنها را دجار درجات مختلف افسردگى (از مرزى تاعئ عميق) نشان

داد[18]

تحقيقات ديگرى در زمينه خانوادههاى جانبازان نشان داد كه در

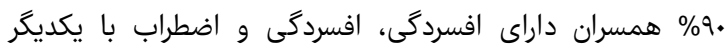

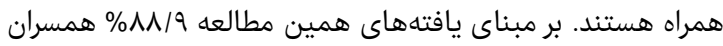

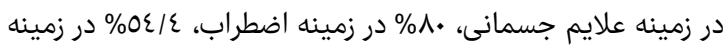

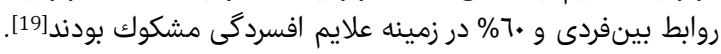

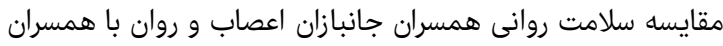

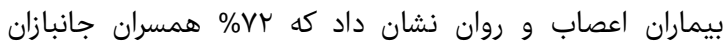

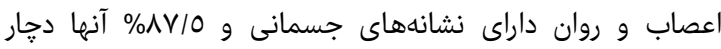

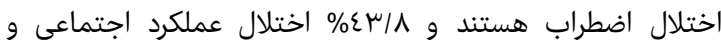

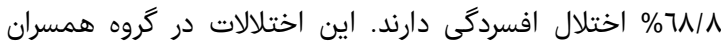

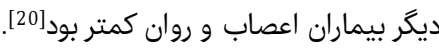

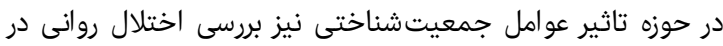

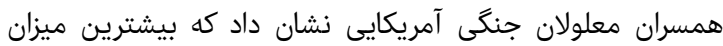

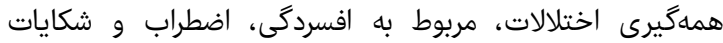

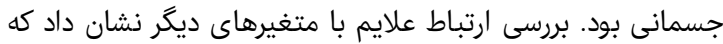

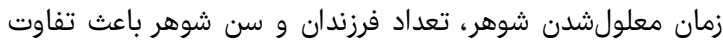

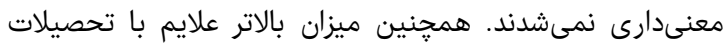

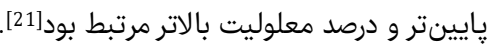

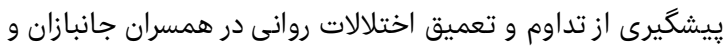

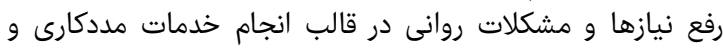

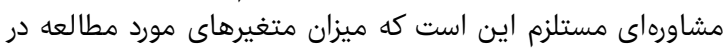

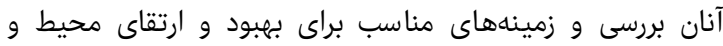

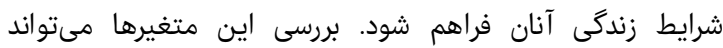

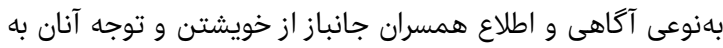

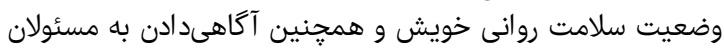

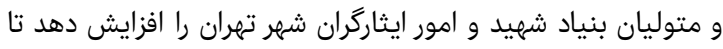

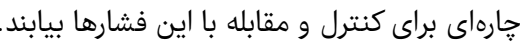

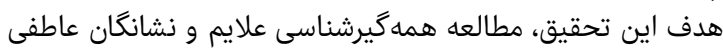

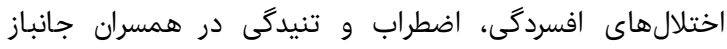

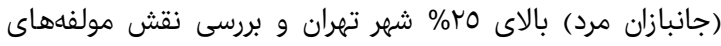

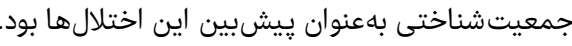

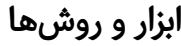

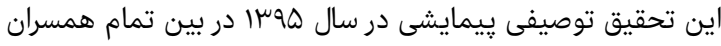

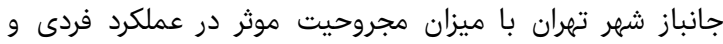

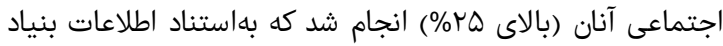

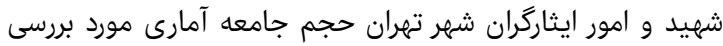

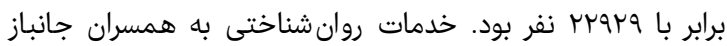

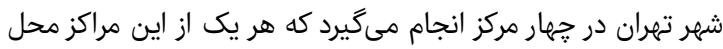

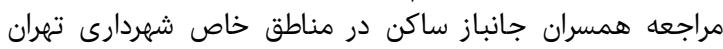

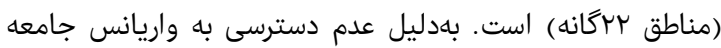

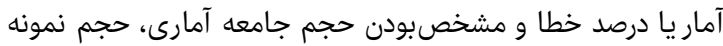

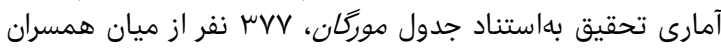


وضعيت سلامت جسمى و يرداختن به فعاليتهاى تفريحى در آنراس

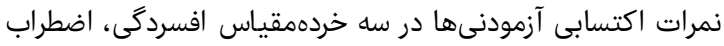

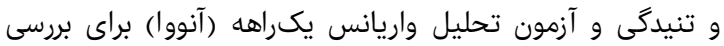

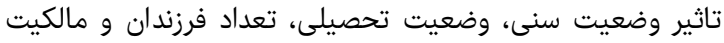

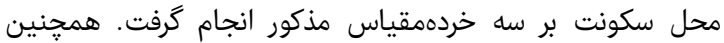

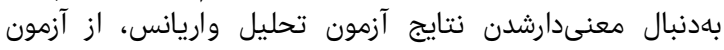
تعقيبى شفه براى مقايسه دوبهدوى گروهها با يكديكر استفاده شد.

\section{يافتهها}

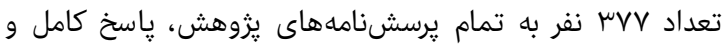

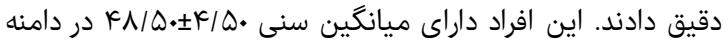

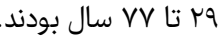

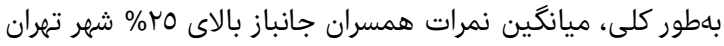

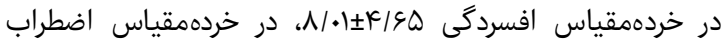

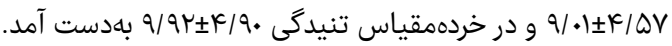

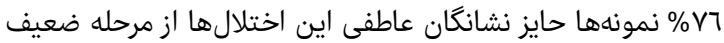

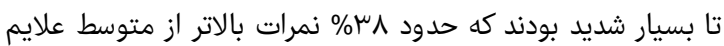

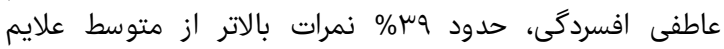

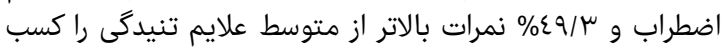

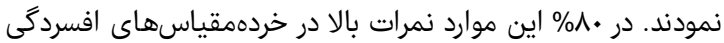

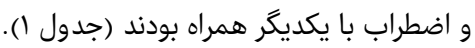

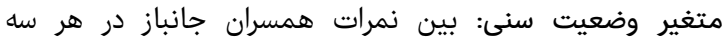

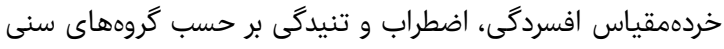

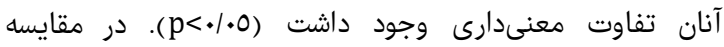

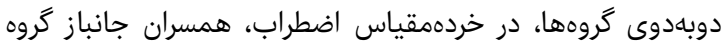

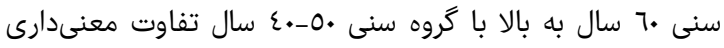

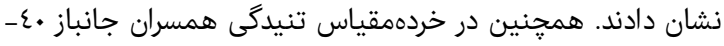

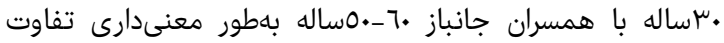

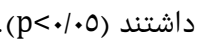

متغير وضعيت تحصيلى: بر حسب متغير سطح تحصيلات همسران

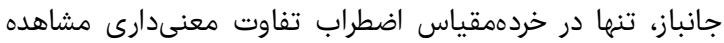

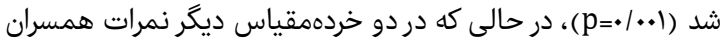

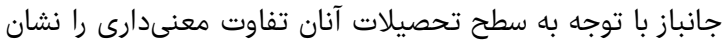

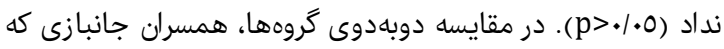

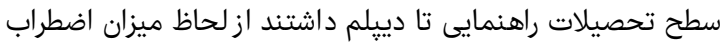

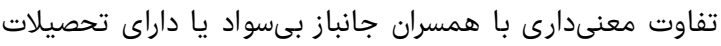

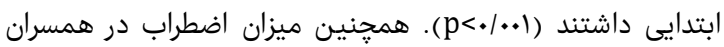

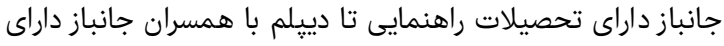

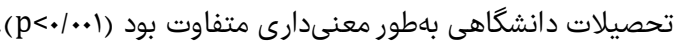

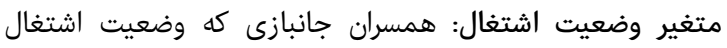

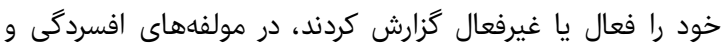

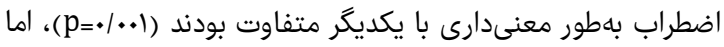

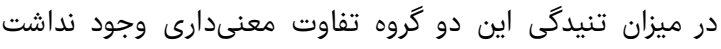

(p=./・7)

متغير وضعيت سلامت جسمى: بيش از نيمى از همسران جانباز

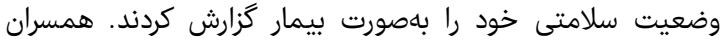
جانبازى كه وضعيت سلامت جسمى خود را سالم يا بيمار كزارش

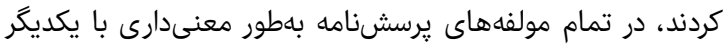

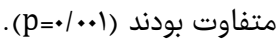

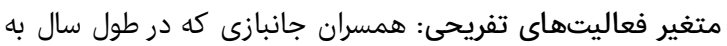

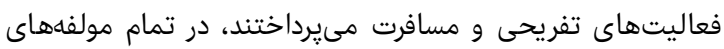

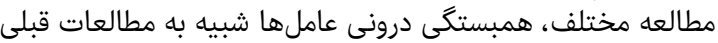

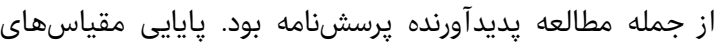

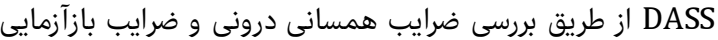

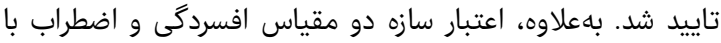

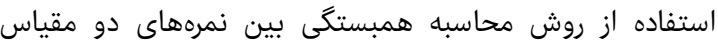

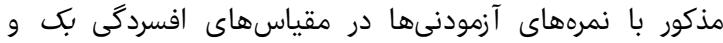

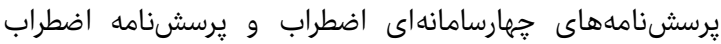

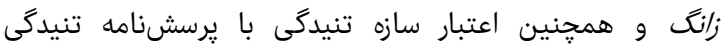

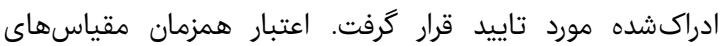

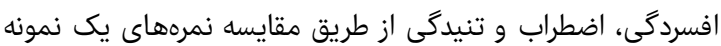

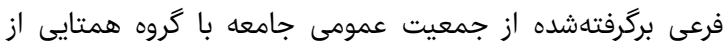

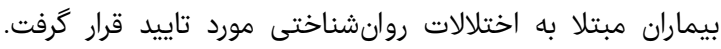

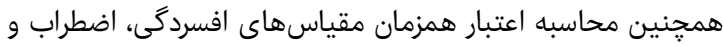

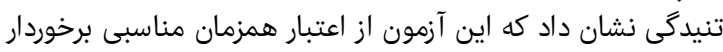

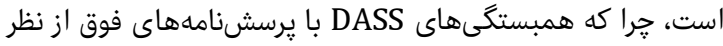

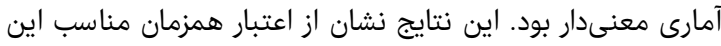

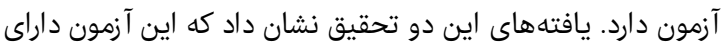

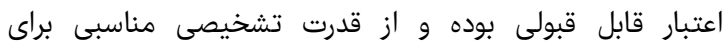

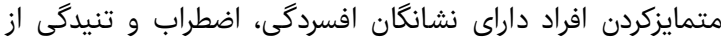

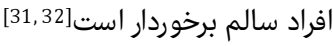

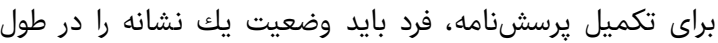

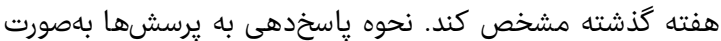

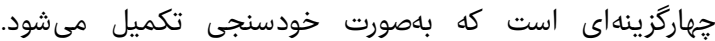

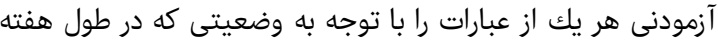

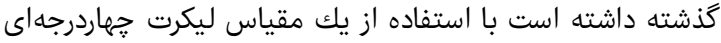

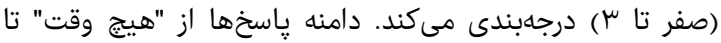

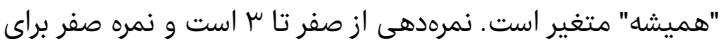

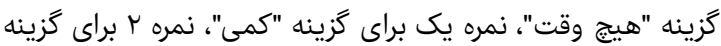

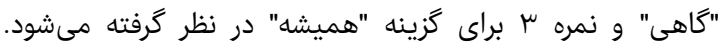

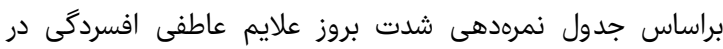

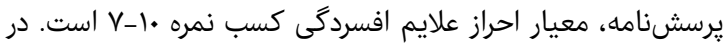

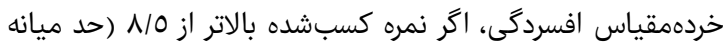

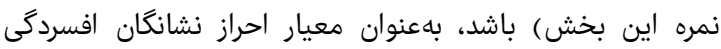

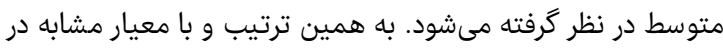

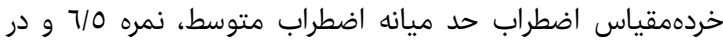

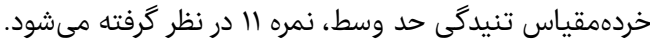

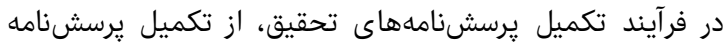

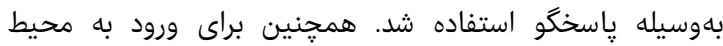

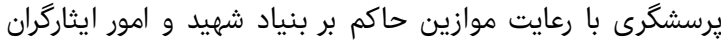

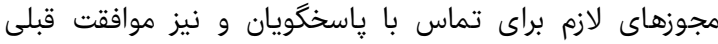
ياسخكويان جلب شد. توضيحات لازم درباره تحقيق، اهداف، نافي نتايج

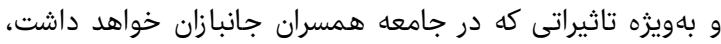

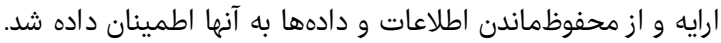

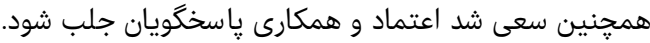

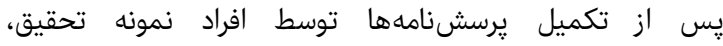

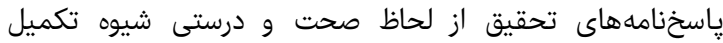

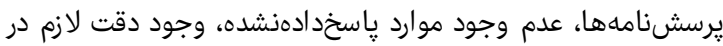

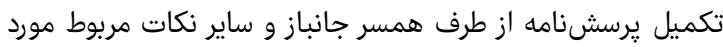

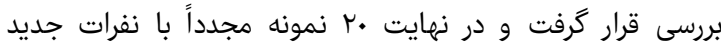

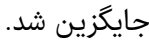
آناليز دادهها با نرمافزار SPS 21 و با استفاده از آزمون TSS مستقل

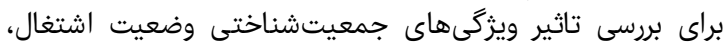




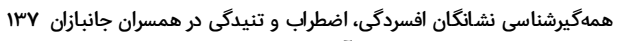

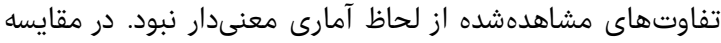

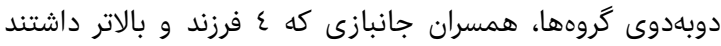

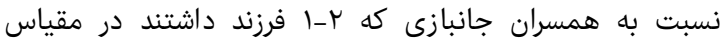

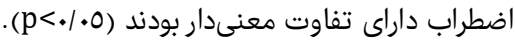

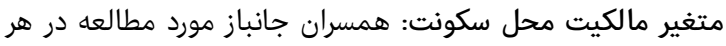

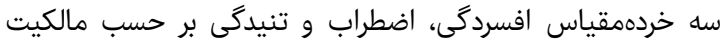

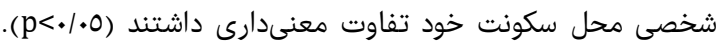

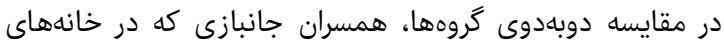

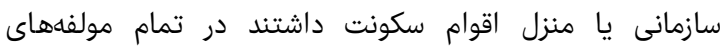

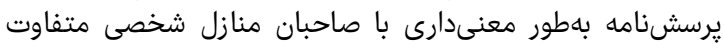

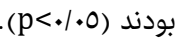

عمدهترين عوامل تنيدگى همسران جانباز يس از مجران مجروحيت شوهر:

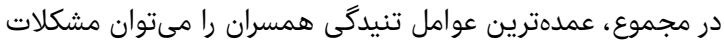

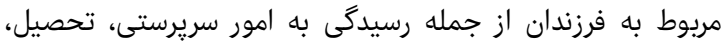

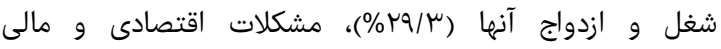

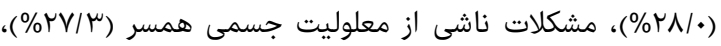

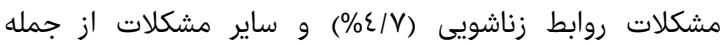

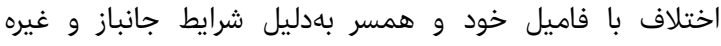

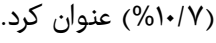

اين تحقيق كاربردى با هدف همهگيرشناسى نشانگًان افسردگى،

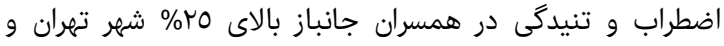

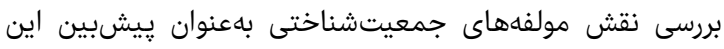

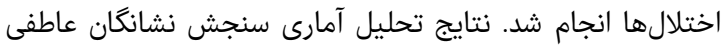

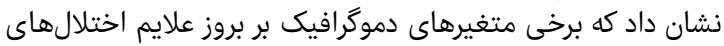

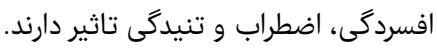

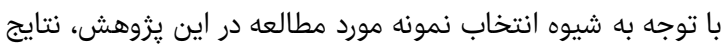

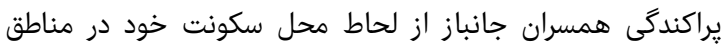

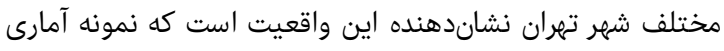

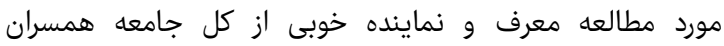

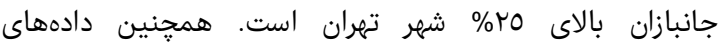

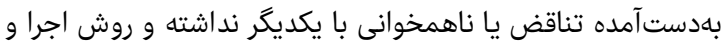

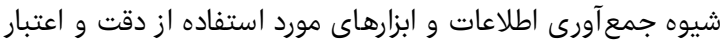
قابل قبولى برخوردار بودهاند.

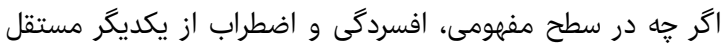

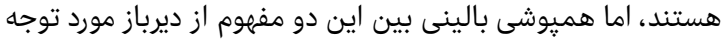

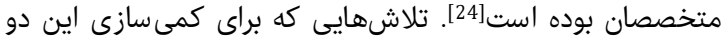

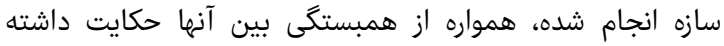

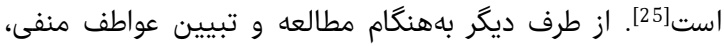

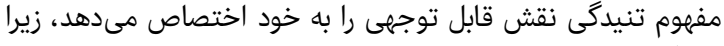

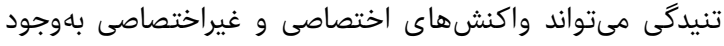

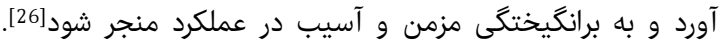

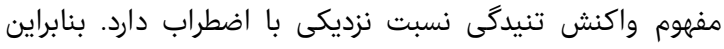

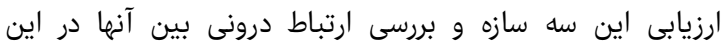

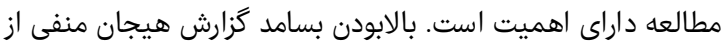

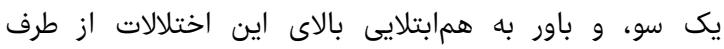

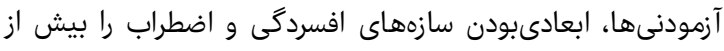

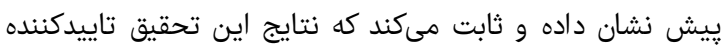

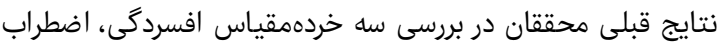

$$
\text { و تنيدگى در آزمودنىها بود [35-33]. }
$$

يرسشنامه بهطور معنىدارى با افرادى كه به تفريح نمىيرداختند

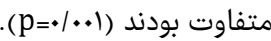

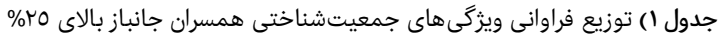

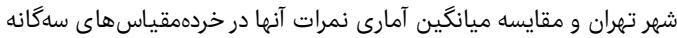

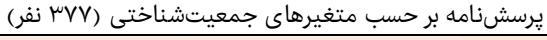

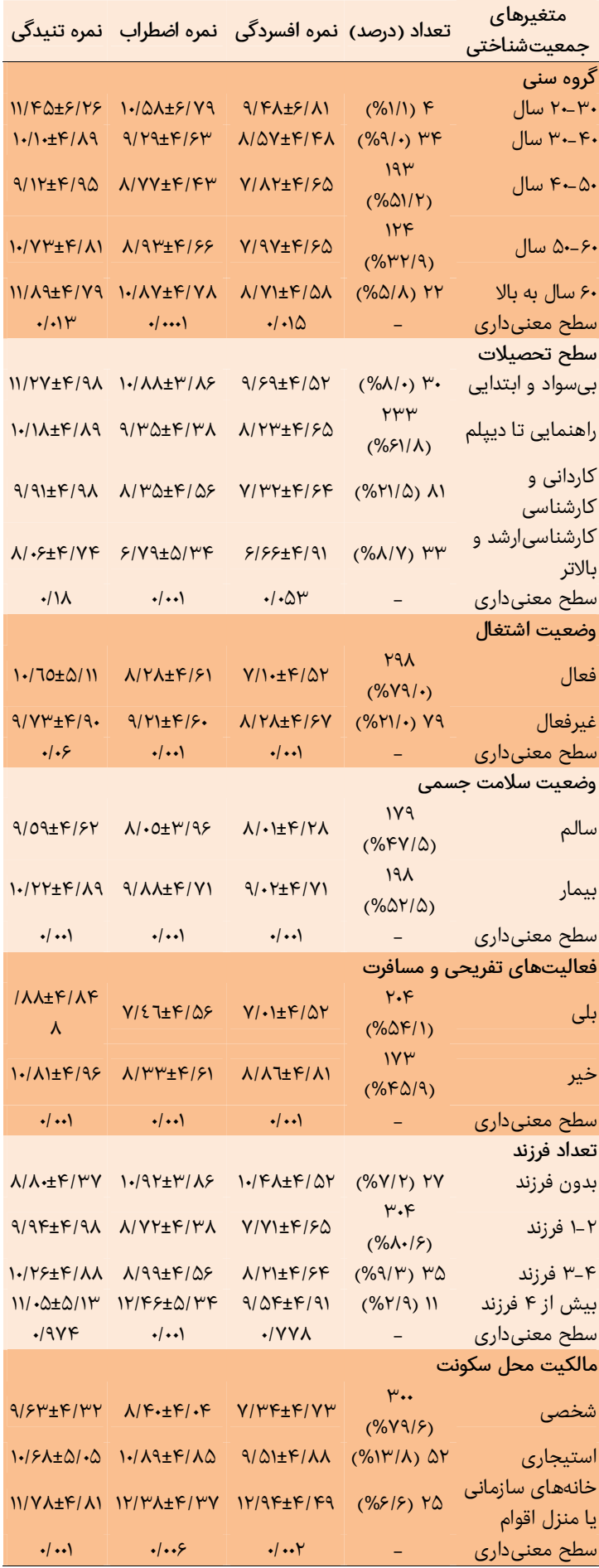

متغير تعداد فرزندان: همسران جانباز مورد مطالعه تنها در ترداب

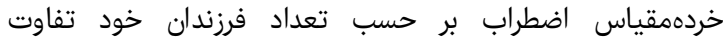

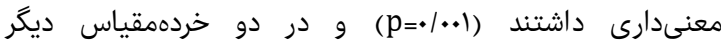


نمره •lV-1 است. اكر نمره كسبشده بالاتر از 1/0 (حد ميانه نمره

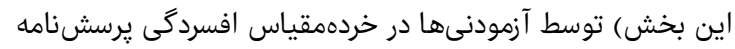

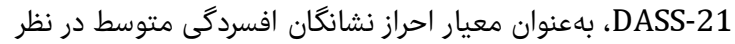

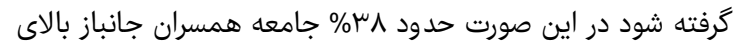

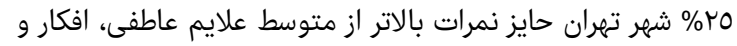

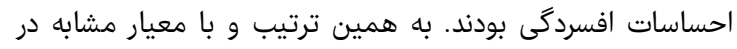

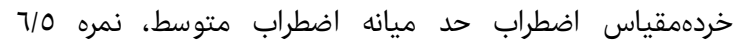

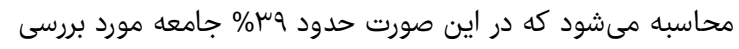

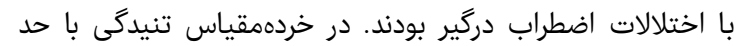

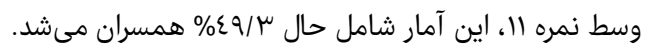

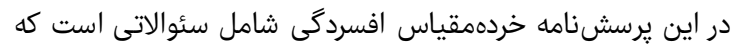

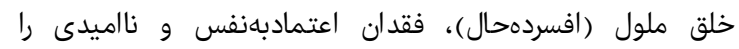

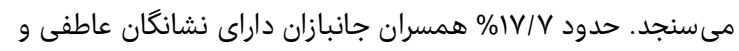

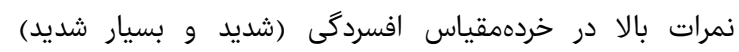

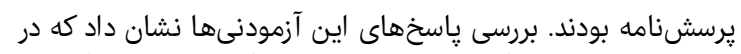

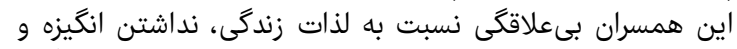

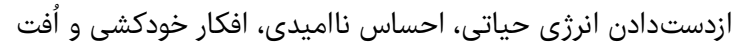

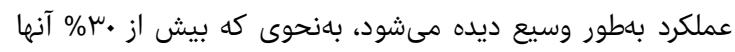
داراى اشتغالات فكرى مربوط به مركى بودئ بودند.

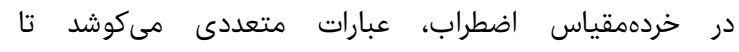

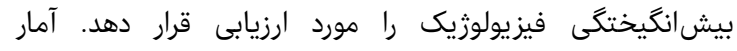

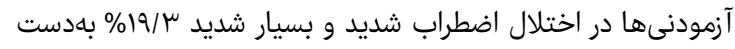

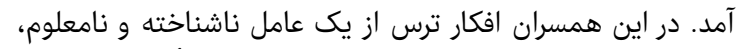

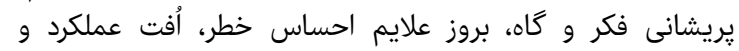

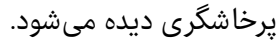

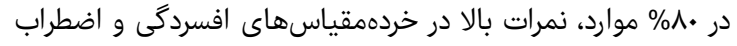

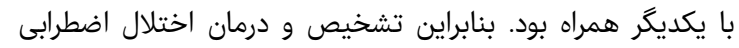

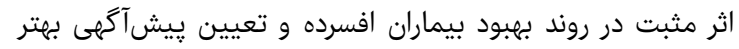

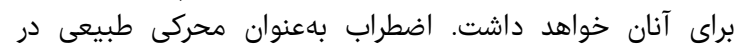

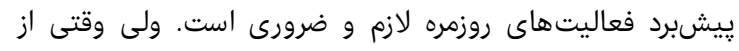

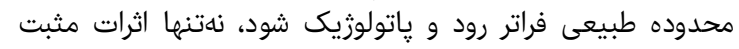

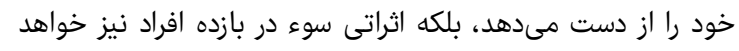

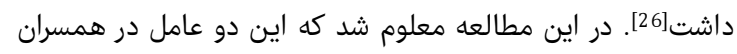

جانباز بيش از افراد عادى است.

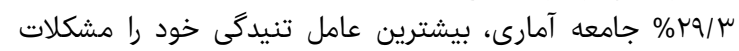

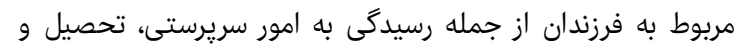

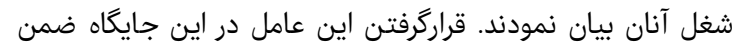

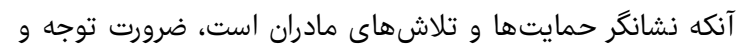

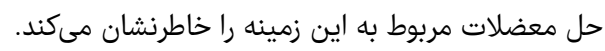

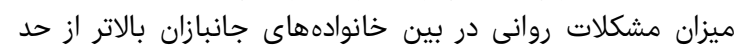

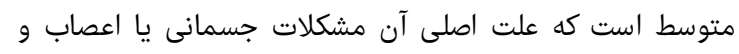

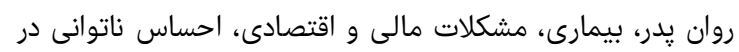

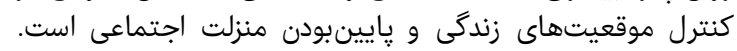

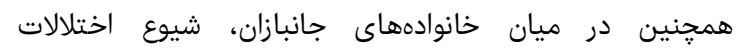

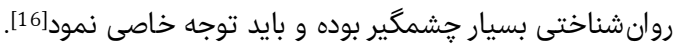

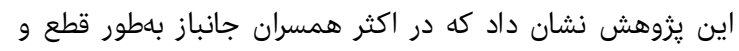

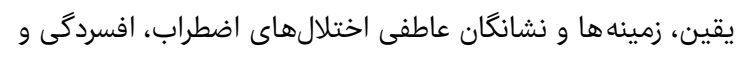

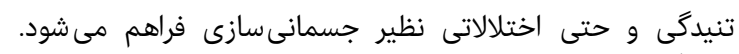

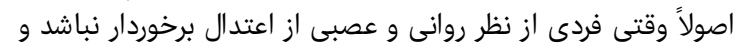

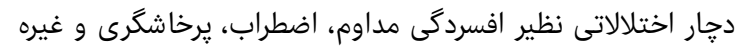

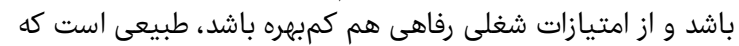
اثرات اين وضعيت روانى بر افكار همسر تاثير سوء كذاشتنه تا آنجا

دوره 9، شماره س، تابستان عهسر

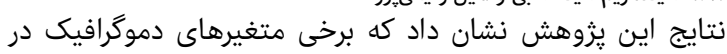

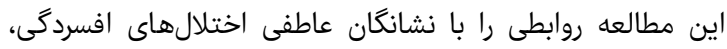

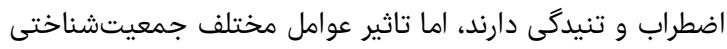

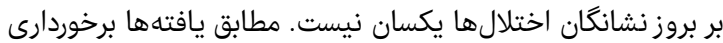

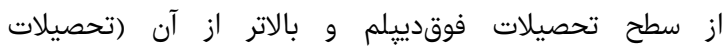

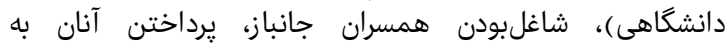

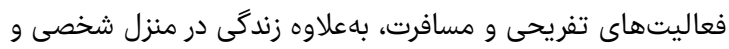

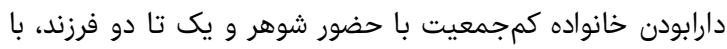

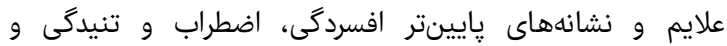
باعبارتى با سلامت روانى آنها همراه است.

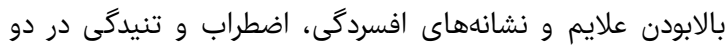

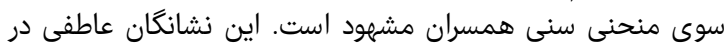

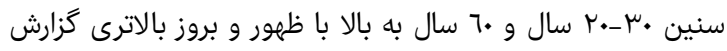

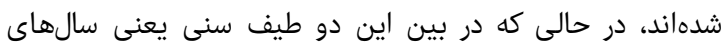

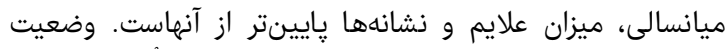

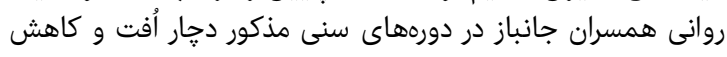

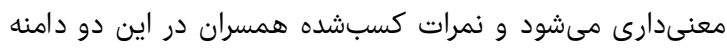

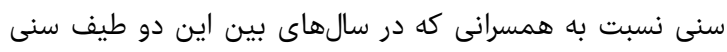

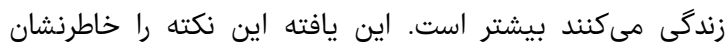

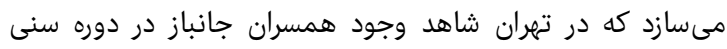

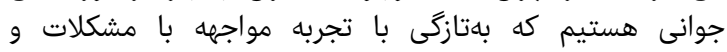

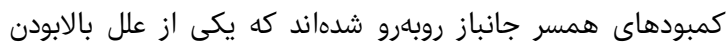

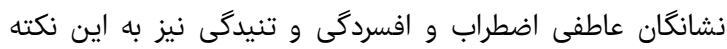

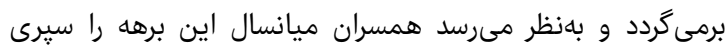

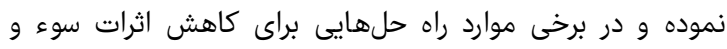

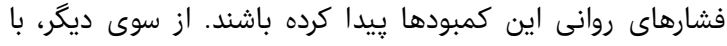

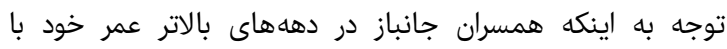

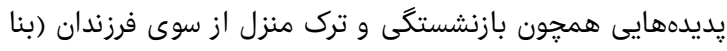

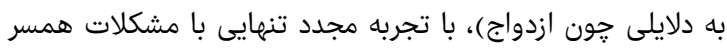

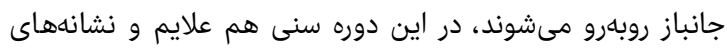

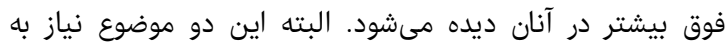

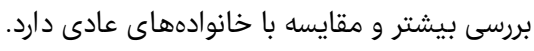

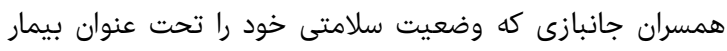

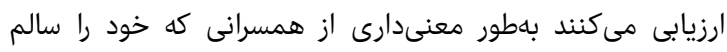

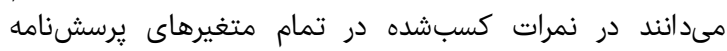

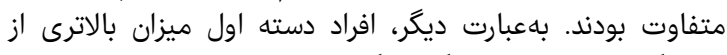

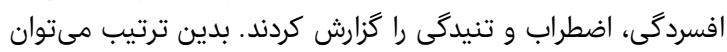

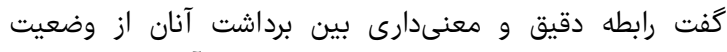

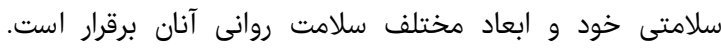

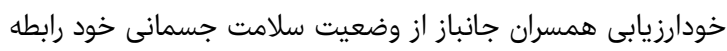

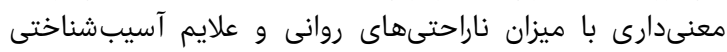

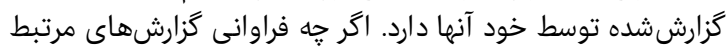

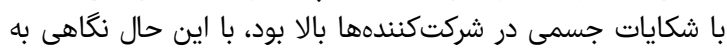

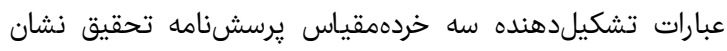

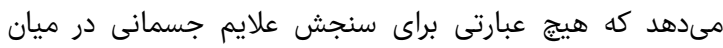

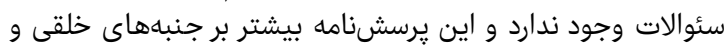

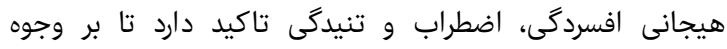

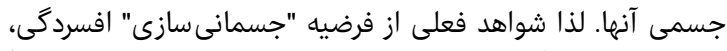

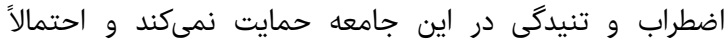

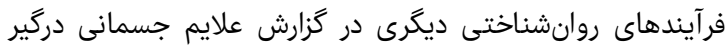

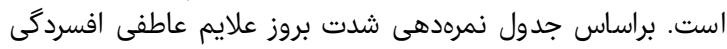

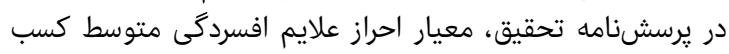




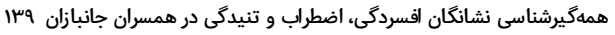

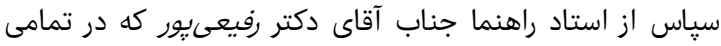
مراحل اين تحقيق راهنماى بنده بودهاند.

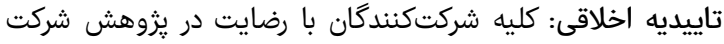

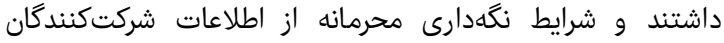
رعايت شده است. تعارض منافع: موردى از طرف نويسندكان بيان نشده است است.

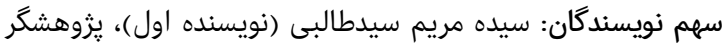

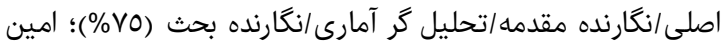

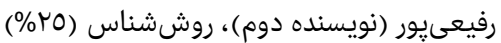

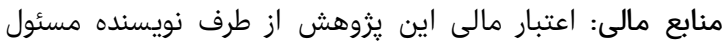
تامين شده است.

\section{منابع}

1- Foster H, Brook-Gunn J. Children's exposure to community and war violence and mental health in four African countries. Soc Sci Med. 2015;146:292-9.

2- Buijck BI, Zuidema SU, Spruit-van Eijk M, Bor H, Gerritsen DL, Koopmans RT. Determinants of geriatric patients' quality of life after stroke rehabilitation. Aging Ment Health. 2014;18(8):980-5.

3- Westphal-Guitti AC, Alonso NB, Migliorini RC, da Silva TI, Azevedo AM, Caboclo LO, et al. Quality of life and burden in caregivers of patients with epilepsy. J Neurosci Nurs. 2007;39(6):354-60.

4- White RF, Steele L, O'Callaghan JP, Sullivan K, Binns JH, Golomb BA, et al. Recent research on Gulf War illness and other health problems in veterans of the 1991 Gulf War: Effects of toxicant exposures during deployment. Cortex. 2016;74:449-75.

5- Al-Turkait FA, Ohaeri JU. Post-traumatic stress disorder among wives of Kuwaiti veterans of the first Gulf War. J Anxiety Disord. 2008;22(1):18-31.

6- Coughlan K, Parkin C. Women partners of Vietnam vets. J Psychosoc Nurs Ment Health Serv. 1987;25(10):25-7.

7- Grieger TA, Cozza SJ, Ursano RJ, Hoge C, Martinez PE, Engel CC, et al. Posttraumatic stress disorder and depression in battle-injured soldiers. Am J Psychiatry. 2006;163(10):1777-83.

8- Jakupcak M, Tull MT, McDermott MJ, Kaysen D, Hunt S, Simpson T. PTSD symptom clusters in relationship to alcohol misuse among Iraq and Afghanistan war veterans seeking post-deployment VA health care. Addict Behav. 2010;35(9):840-3.

9- Kajbaf M, Ghasemiannezhad Jahromi AN, Ahmadi Foroshani SH. The effectiveness of spiritual and existential group therapy on the rates of depression, death anxiety and afterlife belief among students: a study based on the reports of people with death experience. Knowl Res Appl Psychol. 2016;16(4):4-13. [Persian] 10- Dekel R, Goldblatt H, Keidar M, Solomon Z, Polliack $\mathrm{M}$. Being a wife of a veteran with posttraumatic stress disorder. Fam Relat. 2005;54(1):24-36.

11- Babaee E, Jain S, Cardona B, Williams A, Naghizadeh $\mathrm{N}$. Health and marital satisfaction among Iranian women married to veterans and nonveterans. World Appl Sci J. 2009;6(12):1612-6.

12- Jordan BK, Marmar CB, Fairbank JA, Schlenger WE, Kulka RA, Hough RL, et al. Damages in families of male Vietnam veterans with posttraumatic stress disorder. J Consult Clin Psychol. 1992;60(6):916-26.

13- Najafy M, Mohammadyfar MA, Dabiri S, Erfani N, Kamary AA. The Comparison of the quality of life of the
كه او نيز خود گرفتار اختلالات افسردگى، اضطرابى و سازگارى إنى

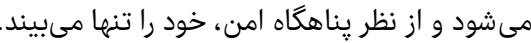

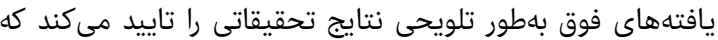

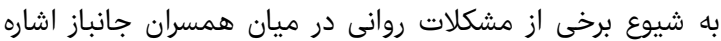

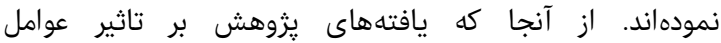

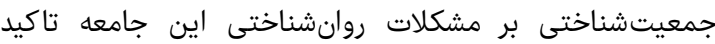

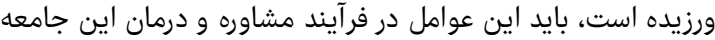

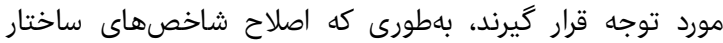

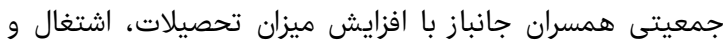

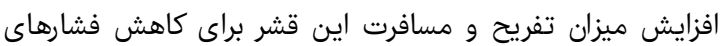

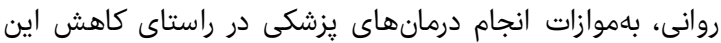

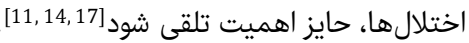
مطالعه حاضر از محدوديتهايى اهيت نيز برخوردار بود؛ از آن آن جمله

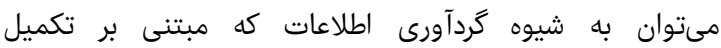

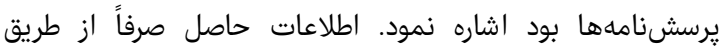

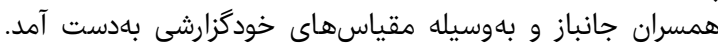

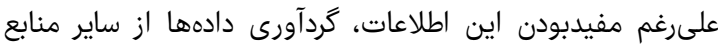

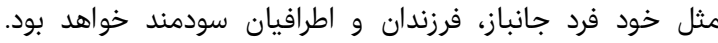

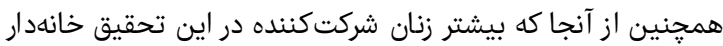

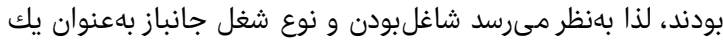

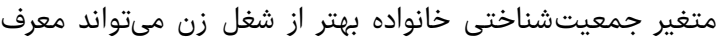

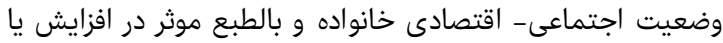

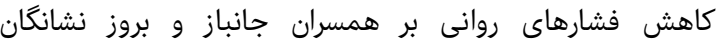

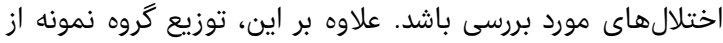

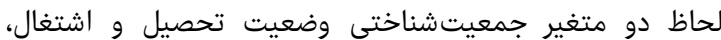

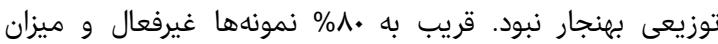

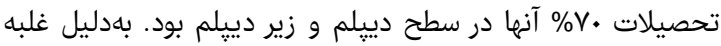

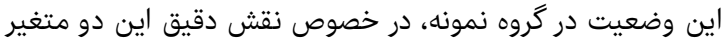

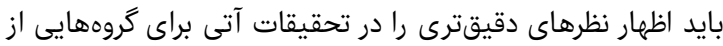

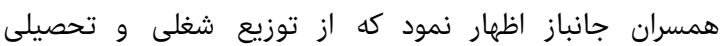
بهنجارترى برخوردار باشند.

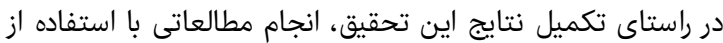

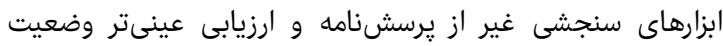

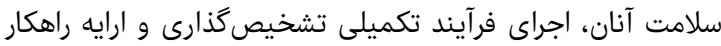

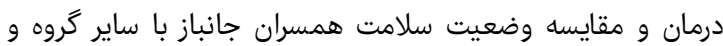

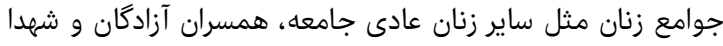
ي بيشنهاد مى شود.

\section{نتيجه}

\% همسران جانباز بالاى \%ro

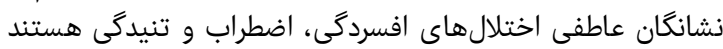

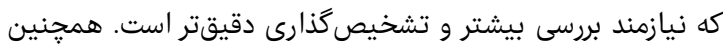

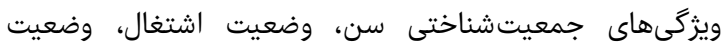

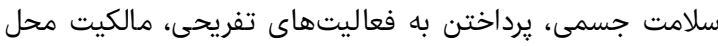

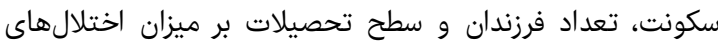

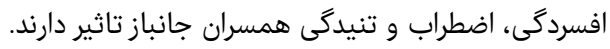

تشكر و قدردانى: از همكارى صميمانه جناب آقاى شاكرى مدير

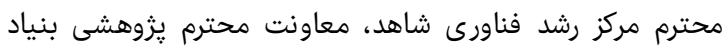

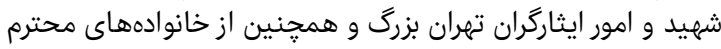

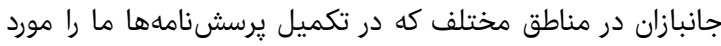

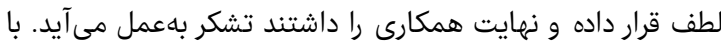


24- Beck AT, Epstein N, Brown G, Steer RA. An inventory for measuring clinical anxiety: Psychometric properties. J Consult Clin Psychol. 1988;56(6):893-7.

25- Beck AT, Ward CH, Mendelson M, Mock J, Erbaugh J. An inventory for measuring depression. Arch Gen Psychiatry. 1961;4:561-71.

26- Derogatis L. SCL $90 \mathrm{R}$ administration, scoring and procedures manual II for the revised version and other instruments of the psychopathology rating scale series. Towson: Clinical Psychometric Research; 1983. pp.14-5. 27- Bajaja B, Robinsb RW, Pandec N. Mediating role of self-esteem on the relationship between mindfulness, anxiety, and depression. Personal Individ Differ. 2016;96:127-31.

28- Lovibond S, Lovibond P. Manual for the depression anxiety stress scales. Sydney, N.S.W.: Psychology Foundation of Australia; 1995.

29- Antony M, Bieling P, Cox B, Enns M, Swinson R. Psychometric properties of the 42-item and 21-item versions of the Depression Anxiety Stress Scales (DASS) in clinical groups and a community sample. Psychol Assess. 1998;10:176-81.

30- Heaven PC, Smith L, Prabhakar SM, Abraham J, Mete ME. Personality and conflict communication patterns in cohabiting couples. J Res Personal. 2006;40(5):829-40.

31- Asghari A, Saed F, Dibajnia P. Psychometric properties of the Depression Anxiety Stress Scales-21 (DASS-21) in a non-clinical Iranian sample. Int J Psychol. 2008;2(2):82-102.

32- Sahebi A, Asghari MJ, Salari RS. Validation of depression anxiety and stress scale (DASS-21) for an Iranian population. J Iran Psychol. 2005;1(4):11-28. [Persian]

33- Li Y, Dai W, Zhang J. Anxiety, depression and quality of life in patients with a treated or untreated unruptured intracranial aneurysm. J Clin Neurosci. 2017; S09675868(16)30635-X.

34- Lazarus RS. From psychological stress to emotions: A history of changing outlooks. Annu Rev Psychol. 1993;44:1-21.

35- Costello CG, Comrey AL. Scales of measuring anxiety and depression. J Psychol. 1967;66(2):303-13. war veterans families with/without Post traumatic stress disorder. Iran J War Public Health. 2011;3(3):2735. [Persian]

14- Jafari F, Moien L, Soroush M, Mosavi B. Quality of life in chemical warfare victims with ophthalmic damage's spouses. Iran J War Public Health. 2011;3(3):8-12. [Persian]

15- Safavi M, Mahmoudi M, Akbarnatajbisheh K. Assessment of relationship quality of life and coping skills in spouses of chemical devotees with pulmonary complications due to sulfur mustard in Tehran in 2006. Daneshvar. 2010;17(87):9-18. [Persian]

16- Radfar Sh, Haghani H, Tavalaei SA, Modirian E, Falahati M. Evaluation of mental health state in veteran's family (15-18 Y/O adolescents). J Mil Med. 2005;7(3):203-9. [Persian]

17- Mojahed A, Kalantari M, Molavi H, Neshat Doost H, Bakhshani N, Shakiba M. Comparative investigation of mental health status of spouses of war handicaps in accordance with husband's disability. Res Med Sci Zahedan J. 2002;12(4):38-2. [Persian]

18- Bahreinian SA, Borhani H. Mental health in a group of war veterans and their spouses in Qom. Res Med. 2003;27(4):305-12. [Persian]

19- Parandeh A, Siratinir M, Khaghanizadeh M, Karimi Zarchi AA. The effect of training conflict resolution on quality of life's on spouses of war veterans post traumatic stress disorder. J Mil Med. 2008;8(1):45-51. [Persian]

20- Bahreynian A, Borhani H. Mental health in a group of war veterans and their spouses in Qom. Res Med. 2003;27(4):305-12. [Persian]

21- Mousavi B, Soroush M, Masoumi M, Ganjparvar Z, Montazeri A. Quality of life in spouses of war related bilateral lower limb amputees. Daneshvar. 2010;17(84):11-8. [Persian]

22- Krejcie RV, Morgan DW. Determining sample size for research activities. Educ Psychol Meas. 1970;30(3):60710.

23- Kerry SM, Bland JM. The intracluster correlation coefficient in cluster randomisation. BMJ. 1998;316(7142):1455-60. 